\title{
PERFORMANCE PARAMETERS OF A CLOSED LOOP THERMOSYPHON
}

Devices composed of output electronic components produce waste heat that has to be dissipated to the environment. Heat removal by means of forced convection air cooling is quite often insufficient and new alternatives for cooling of output electronic components are being looked for. One option is the use of a closed loop thermosyphon. Theclosed loop thermosyphonis a simple and reliabledevice providing heat transfer. The paper deals with the cooling of an output electronic component by means of this device. It describes a design and construction of the device to provide heat removal from the electronic component, measurement of dependences of performance parameters on waste performance of the electronic component and their verification by means of a mathematic calculation based on physical phenomena of boiling, condensation and heat transfer.

Keywords: Closed loop thermosyphon, heat transfer, Fluorinert FC-72, mathematical model

\section{Introduction}

Permanent development of electrotechnical devices aims to increase their performance, to efficiently use the space, to reduce their mass, to achieve higher efficiency and reliability as well as a higher technological level. Another trend in the development of electrotechnical components is miniaturization of dimensions which leads to the increase in local heat loading due to heat waste of electronic components. More intense heat production and its insufficient removal often cause deterioration of electronic system parameters and electronic components failures. To maintain suitable working conditions it is necessary to dissipate waste heat. From various cooling methods used in electronics the heat pipe seems to be one of highly efficient and reliable way of heat removal[1]. The closed loop thermosyphon works on the same principle as the standard gravitational heat pipe in which heat transfer occurs due to the flow of vapor and liquid phase of the working fluid between the evaporation and condensation sections of the heat pipe. The difference between them is in the way of the working fluid circulation. While in the standard gravitational heat pipe theworkingfluid flows between the evaporation and condensation sections in the same space, in the closed loop thermosyphon the working fluid flows in a closed loop between the evaporation and condensation sections. Due to the absence of interaction and reverse flow of vapor and liquid phase the closed loop thermosyphon features better ability to heat transfer between its evaporation and condensation sections than the standard gravitational heat pipe.

\section{Construction of the closed loop thermosyphon}

Main parts of the closed loop thermosyphon are:

- evaporator,
- condenser,

- pipe system to transport the working fluid and

- inlet and closing valves.

The evaporator (Fig. 1) enables on the base of a phase change (boiling) of the working fluid an intensive heat removal from its surface. It has to be constructed so that it will prevent the leakage of the working fluid, maintain pressure differences in all the walls and enable heat transfer from the electronic component into the working fluid as well as a suitable distribution of liquid and vapor phases of the working fluid. When choosing the material suitable for the construction of evaporator, it is necessary to pay attention to its thermokinetic characteristics. To provide a minimal temperature drop between a heat source and evaporator, the evaporator material must feature high thermal conductivity. To prevent escape of vapor, it should not be porous. The material should have high strength but, at the same time, it should be easily machineable and compatible with the working fluid [2]. Fig. 1 shows the closed loop thermosyphon from aluminum alloy designed with respect to the above requirements. The evaporator body is a plate with dimensions $116 \times 80 \times 30 \mathrm{~mm}$. To provide the working fluid circulation there are two 12 mmopeningsdrilled horizontally on the plate and connected with nine $6 \mathrm{~mm}$ vertical connecting channels. They provide the transport of heated fluid vapor from the bottom to the top section of the evaporator. On the outer contact surface of the evaporator and electronic component there is a groove with a mounted temperature sensor.

The closed loop thermosyphon condenser (Fig. 2) is a soldering plate heat exchanger Alfa Laval. This choice was determined by the effort to achieve a compact construction of the cooler providing the working fluid cooling in the heat pipe at defined temperatures of the cooling water and being able to withstand high

\footnotetext{
* Patrik Nemec, Milan Malcho, Martin Smitka, Jozef Matusov

Department of Power Engineering, Faculty of Mechanical Engineering, University of Zilina, Slovakia, E-mail: patrik.nemec@fstroj.uniza.sk,
} 

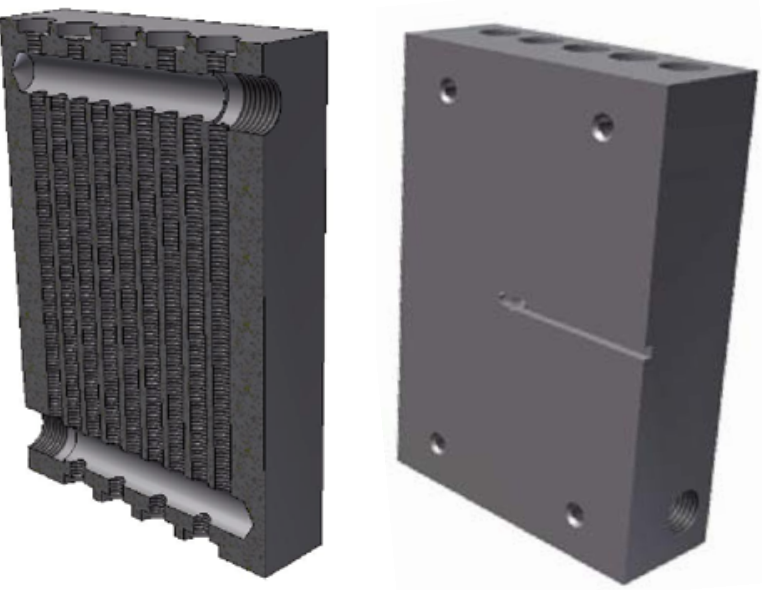

Fig. 1 Loop thermosyphon evaporator

pressures. Soldering plate heat exchangers comprise a stack of shaped plates pressed of stainless steel. Corrugation of plates ensures more intense heat transfer and at the same time increases their rigidity.

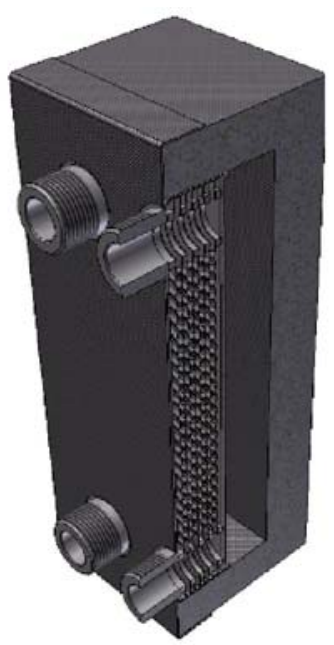

Fig. 2 Loop thermosyphon condenser

Heat exchanger plates are arranged so that there are optimal channels among them into which heat carrying fluid is introduced through openings in the corners of the plates. Each plate is flown by the primary fluid from one side and by the secondary fluid from another side with simultaneous presence of heat transfer. A copper connector connects the plates not only along their circumference but also in all connecting places of neighboring plates. Brazed heat exchangers are therefore able to withstand high temperatures (up to $225^{\circ} \mathrm{C}$ ) and pressures (up to 49 bars) and have high efficiency of heat transfer even at low logarithmic mean temperature difference. The transport section of the closed loop thermosyphon provides the circulation of vapor and liquid phases between the evaporator and condenser of the heat pipe. The whole transport section consists of $10 \mathrm{~mm}$ copper connecting tubes. Transient glass tubes were mounted on the evaporation and condensation sides of the transport section of the heat pipe to visualize and check the working fluid flow. All connecting transient points of the whole heat pipe system are vacuum-tight. The intake and closing valves are located on the top of the evaporation transport section.

\section{Working fluid}

The first criterion for a design of suitable working fluid is the range or operating temperature. As there can be more working fluids within the range of suitable operating temperatures, it is, therefore, necessary to observe and compare their further thermophysical characteristics when determining the most suitable one. The main requirements for working fluid characteristics are compatibility with the heat pipe material, good temperature stability, suitable vapor pressure, large latent heat of evaporation, high thermal conductivity, low viscosity of fluid and vapor, acceptable point of freezing and solidification from the point of cooling operation.

The choice of working fluid has also to be done on the basis of thermodynamic considerations concerning various limitations of heat transfer in heat pipes (viscose, sonic, capillary limits and limits of bubble boiling). Vapor pressure within the range of operating temperatures has to be sufficiently large to avoid high velocity of vapor which may cause instability of heat flows. The working fluid must feature high latent heat of evaporation which will enable to transfer the highest possible amount of heat with the least fluid flow provided the low pressure difference in the heat pipe is maintained. Thermal conductivity of the working fluid should be, if possible, high to minimize radial temperature gradient and decrease possibilities of film boiling on the surface walls. The resistance to the fluid flow is minimized through the choice of fluid with low values of viscosity of fluid and vapor phases [3]. In compliance with

Physical characteristics of working fluid FC 72

Table 1 at temperature $20{ }^{\circ} \mathrm{C}$ [4].

\begin{tabular}{|l|c|c|}
\hline \multicolumn{3}{|c|}{ FC 72 CHARACTERISTICS } \\
\hline Relative molecular mass & - & 338 \\
\hline Estimatedcritical temperature & $\mathrm{K}$ & 449 \\
\hline Estimatedcritical pressure & $\mathrm{MPa}$ & 1.83 \\
\hline Vapor pressure & $\mathrm{kPa}$ & 30.9 \\
\hline Latent heat of evaporation(at nor. boiling point) & $\mathrm{kJ} \cdot \mathrm{kg}^{-1}$ & 88 \\
\hline Density of fluid & $\mathrm{kg} \cdot \mathrm{m}^{-3}$ & 1680 \\
\hline Kinematic viscosity & $\mathrm{m} 2 . \mathrm{s}^{-1}$ & $0.38 .10^{-6}$ \\
\hline Specific heat of fluid & $\mathrm{Jkg}^{-1} \mathrm{~K}^{-1}$ & $1100 \mathrm{~J}$ \\
\hline Thermal conductivity of fluid & $\mathrm{Wm}^{-1} \mathrm{~K}^{-1}$ & 0.057 \\
\hline Coefficient of expansion & $\mathrm{K}^{-1}$ & 0.00156 \\
\hline Surface tension & $\mathrm{N} \cdot \mathrm{m}^{-1}$ & $10^{-2}$ \\
\hline Dielectric strength & $\mathrm{kV}$ & 38 \\
\hline Dielectric constant & - & 1.75 \\
\hline
\end{tabular}


the above mentioned conditions Fluorinert FC 72 was chosen as the working fluid for experimental research of the heat pipe, due to its compatibility with most metals, low boiling temperature $\left(56{ }^{\circ} \mathrm{C}\right)$ and solidification $\left(-90{ }^{\circ} \mathrm{C}\right)$ and, first of all, due to its excellent dielectric characteristics. Physical characteristics of Fluorinert FC 72 are presented in Table 1 .

\section{Measurement of loop thermosyphon performance parameters}

To determine the heat pipe performance parameters a measuring device was designed - its scheme can be seen in Fig. 3. Due to possible applications of the heat pipe system serving,for example, also heat transfer in a region with the temperature of $50{ }^{\circ} \mathrm{C}$, measurements with the maximum input temperature of the cooling fluid up to $50{ }^{\circ} \mathrm{C}$ were made. The measurement was performed at the increasing waste heat performance of the electronic element from 20 to $370 \mathrm{~W}$. The electronic element fixed in a standard way to the evaporation section of the heat pipe was connected to the unidirectional current source HEWLET PACKARD 6575A, DC POWER SUPLY $0-120 \mathrm{~V} /$ 0-18.5 A. The maximum admissible electric current that can pass through the electronic component was $20 \mathrm{~A}$ at the maximum voltage $20 \mathrm{~V}$ and the highest admissible temperature on the contact surface was $100{ }^{\circ} \mathrm{C}$. Supplying the required heat to the evaporation section of the heat pipe, the working fluid is heated to the boiling point and starts to evaporate. Vapors of the working fluid flow along the tubes of the evaporation section of the heat pipe to its condensation section which is formed by a plate heat exchanger. Vapors of the working fluid condense on the cooling surface of the heat exchanger plates connected to the cooling circulation with a thermostat. Due to gravity the liquid phase of the working fluid flows back to the evaporator of the heat pipe.

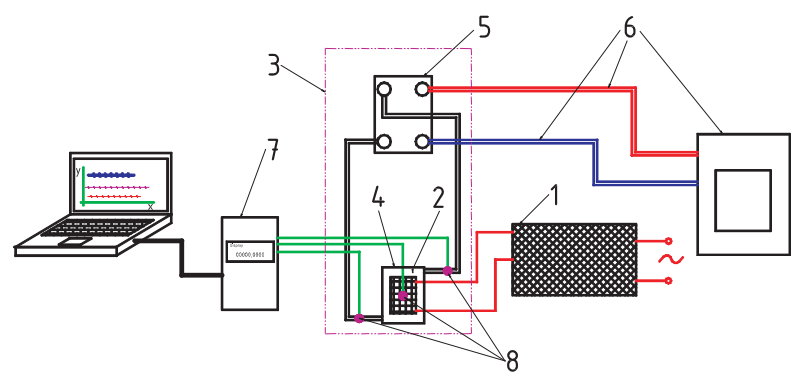

Fig. 3 Scheme of measurement device connection 1- source of electric voltage and power, 2 - testing electronic component, 3 -closed loop thermosyphon, 4 -evaporator, 5 - condenser, 6 -cooling circuit with thermostat, 7 - measurement centre, 8 - temperature sensors (thermocouples)

$\mathrm{Ni}-\mathrm{CrNi}$ thermocouples reading surface temperatures are connected to the evaporation and condensation sections of the closed loop thermosyphon and to the connecting surface of the electronic component and evaporator. The temperatures are recorded into a PC by means of software AMR32in the measurement centre. Figure4 shows the closed loop thermosyphon connected to the measurement devices.

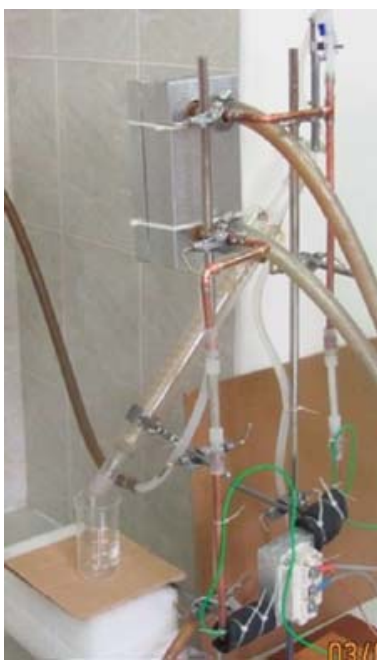

Fig. 4 Closed loop thermosyphon

Performance of the electronic component was gradually increased in five minute intervals by $40 \mathrm{~W}$. To measure the heat performance more than $40 \mathrm{~W}$,the time interval was extended to 31 minutes due to the recorded instability. Time intervals were not chosen randomly; they were determined from previous experiments and observation of the time interval of the stabilization of the measured closed loop thermosyphon. Results gathered from the measurement are shown in Fig. 5.

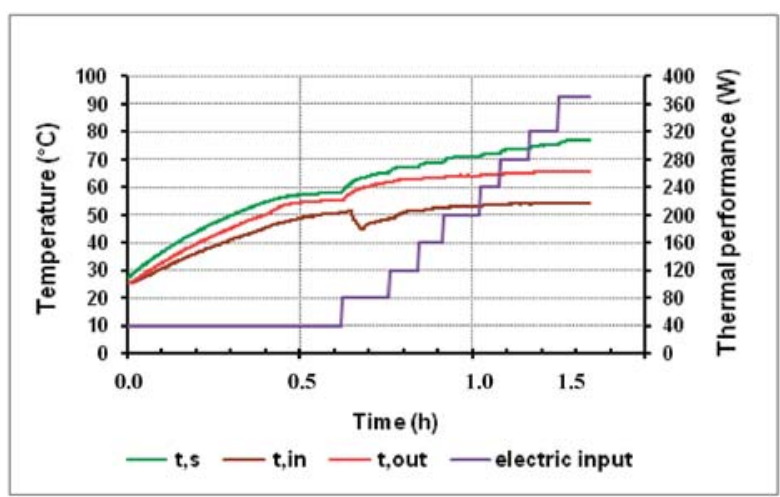

Fig. 5 Temperature dependence in the loop thermosyphon with cooling circulation $50{ }^{\circ} \mathrm{C}$ on performance of the electronic component

Fig. 5 shows the course of wet vapor temperature of the working fluid leaving the evaporator tout, of temperatures of the condensed working fluid entering the evaporator tin and temperatures on the 
contact surface of the evaporator with the electronic component tsdependent mainly on the heat performance of the electronic component. At 0.64 hoursthe temperature of condensed working fluid entering the evaporator drops from $50.6{ }^{\circ} \mathrm{C}$ to $45.4{ }^{\circ} \mathrm{C}$. This drop was caused by more intense bubble formation in boiling and pushing colder working fluid from the plate exchanger into the evaporator. As there was no further drop of the working fluid input temperature during the measurement, the operation of the closed loop thermosyphon was stabilized. Results gathered from the measurement can be used for the creation and comparison of a mathematical model for the calculation of performance parameters of the closed loop thermosyphon with an appropriate working fluid charge.

\section{Mathematical model for determination of performance parameters of the closed loop thermosyphon}

The closed loop thermosyphon has an evaporation section separated from the condensation section, i.e., it has a separate section for a vapor and liquid phase of the working fluid. In the evaporation section of the closed loop thermosyphon the condensate is heated up to the boiling temperature of the working fluid. Boiling temperature is given by instantaneous absolute pressure in the circuit of the closed loop thermosyphon. It can be seen from the experiments that at the temperatures up to approx. $80{ }^{\circ} \mathrm{C}$ the evaporation or bubble boiling of the working fluid FC 72 takes place. The mathematical model of performance parameters of the closed loop thermosyphon was created on the basis of criterion equations (1a) and (1b) just for the bubble boiling [5].

$$
\begin{aligned}
& N u_{B}=0.0625 \cdot \operatorname{Re}_{B}^{0.5} \cdot \operatorname{Pr}_{K}^{0.333} \text { pre } 10^{-5} \leq R e \leq 10^{-2} \\
& N u_{B}=0.125 \cdot \operatorname{Re}_{B}^{0.65} \cdot \operatorname{Pr}_{K}^{0.333} \text { pre } 10^{-2} \leq \operatorname{Re} \leq 10^{4}
\end{aligned}
$$

The Prandtl number is determined from relation (2)

$$
\operatorname{Pr}=\frac{v_{l}}{a}
$$

where $a$ is thermal conductivity

$$
a=\frac{\lambda_{l}}{\left(\rho_{l} \cdot c_{p}\right)}
$$

Reynolds number for boiling is

$$
R e=\frac{q \cdot B}{l_{v} \cdot \rho_{v} \cdot v_{l}}
$$

where $B$ is the critical average of vapor bubble and $q$ is the density of thermal fluid flow,

$$
\begin{aligned}
& B=\frac{c_{p} \cdot \rho_{l} \cdot \sigma \cdot T_{v}}{\left(l_{v} \cdot \rho_{v}\right)^{2}} \\
& q=\frac{p_{e l}}{S}
\end{aligned}
$$

From relation (1a) or (1b) the Nusselt criterion $N u_{B}$ is determined and substituting relation (7), theheat transfer coefficient $\alpha$ is expressed

$$
N u_{B}=\frac{\alpha \cdot B}{\lambda_{l}}
$$

The temperature on the contact area of the fluid and inner area of the evaporator chambers $T s_{v}$ is calculated according to relation (8)

$$
T_{s v}=\frac{\left(q+\alpha \cdot T_{v}\right)}{\alpha}
$$

The temperature on the contact area of the electronic component and the outer area of the evaporator of the closed loop thermosyph $T s$ is calculated from relation (9) that was derived from relations for heat conduction and transfer (10) and (11)

$$
\begin{aligned}
& T_{s}=\left(\frac{q \cdot \delta}{\lambda_{D}}\right)+T_{s v} \\
& q=\lambda D \cdot \frac{T_{s}-T_{s v}}{\delta} \\
& q=\alpha \cdot\left(T_{s v}-T_{v}\right)
\end{aligned}
$$

Basic physical characteristics of FC 72 in dependence on temperature are given by the manufacturer in tables or analytical form from which it is possible to determine the required variables in dependence on temperature

$$
\begin{aligned}
& c_{p}=1014+1.554 .\left(\mathrm{t},{ }^{\circ} \mathrm{C}\right) \\
& \lambda_{l}=0.06-0.00011 .\left(\mathrm{t},{ }^{\circ} \mathrm{C}\right) \\
& \rho_{t}=1740-2.61 .\left(\mathrm{t},{ }^{\circ} \mathrm{C}\right) \\
& p_{v}=10\left(9.729-\frac{1562}{\left(T,{ }^{\circ}\right)}\right)
\end{aligned}
$$

According to the above mentioned relations the mathematical model was created and for the purpose of comparison the values of temperature tsfor the closed loop thermosyphon with the temperature of the cooling circulation in the condenser $50{ }^{\circ} \mathrm{C}$ were

Comparison of calculated and measured temperature $t_{s}$

Table 2 of the closed loop thermosyphon in dependence on temperature $t_{\text {ou }}$

\begin{tabular}{|c|c|c|c|}
\hline$P_{e l}[\mathrm{~W}]$ & $t_{\text {out }}$ (measured) $\left[{ }^{\circ} \mathrm{C}\right]$ & $t_{s}$ (measured) $\left[{ }^{\circ} \mathrm{C}\right]$ & $t_{s}$ (calculated) $\left[{ }^{\circ} \mathrm{C}\right]$ \\
\hline 40 & 30 & 33.71 & 37.66 \\
\hline 40 & 40 & 44.39 & 47.23 \\
\hline 40 & 50 & 54.63 & 56.85 \\
\hline 80 & 60 & 63.5 & 68.46 \\
\hline 320 & 65 & 74.37 & 80.5 \\
\hline
\end{tabular}


calculated. The calculation started from the condition $t_{v}=t_{\text {out }}$ (evaporation temperature of the evaporating working fluid FC 72). Table 2 and Fig. 6 show comparison of calculated and measured values of temperature tsof the closed loop thermosyphon in dependence on the measured evaporation temperature of the working fluid $\mathrm{FC} 72$ tout in a range from $30{ }^{\circ} \mathrm{C}$ to $65^{\circ} \mathrm{C}$.

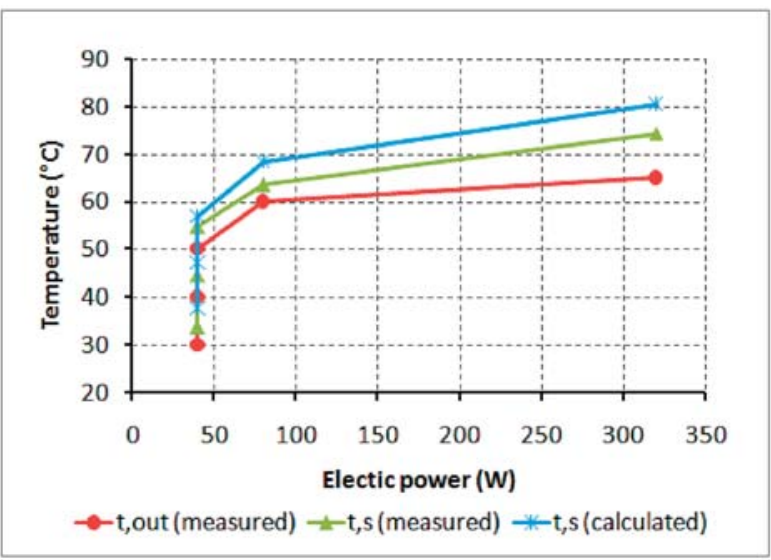

Fig. 6 Comparison of calculated and measured temperature loop thermosyphon evaporator $t_{s}$ in dependence on temperature $t_{\text {out }}$

Fig. 6 shows calculated and measured temperatures tsof the heat pipe in dependence on temperature tout. It is obvious from the courses of temperatures that the measured values differ from the calculated ones only by approx. 3 to $6{ }^{\circ} \mathrm{C}$. This closeness of the results approves the correct functionality and technological procedure of the heat pipe prototype as well as the option to use the simplified mathematical model for dimensioning of cooler with heat pipes for similar electronic components or systems.

\section{Conclusion}

The objective of experiment was to design and construct a prototype of the closed loop thermosyphone and verify its functionality at the cooling of electronic component used in real applications at the highest admissible temperature on the contact area with the cooler $100{ }^{\circ} \mathrm{C}$ and maximum admissible voltage and current $20 \mathrm{~V}$ and $20 \mathrm{~A}$. Another objective of activities also was to show on a simple mathematical model the potential for the cooling of the heat pipe system and compare the resultant values of calculated and measured temperatures on the contact area of the cooled electronic component. According to the experimental measurements and calculations the closed loop thermosyphon cooling proved its high efficiency, which can be also seen at the full performance of the electronic component and also as the highest temperature of the cooling water $50^{\circ} \mathrm{C}$ used to cool the evaporating working fluid in the condenser. The temperature on the contact area of the electronic component with the heat pipe evaporator was always below $80{ }^{\circ} \mathrm{C}$. This experiment approves the cooling quality of the closed loop thermosyphon and justification of its use for the cooling of high efficiency electronic components and systems generating huge thermal flows of waste heat. The use of heat pipes for the cooling of output electronics, mainly electronic semiconductor elements, offers, together with reduced requirements for quantity of constructional material and saved space, also better cooling performance and improved cooling in the area of higher waste heat output above $100 \mathrm{~W}$.

\section{Acknowledgement}

This paper was written within the framework of the project APVV 0577-10.

\section{References}

[1] HARTENSTINE, J., BONNER III, R., MONTGOMERY, J., SEMENIC, T.: Loop ThermosyphonDesign for Cooling of Large Area, High Heat Flux Sources. Proc. of IPACK 2007, Vancouver, CANADA

[2] RUPPERSBERG, J. C., DOBSON, R. T.:Flow and Heat Transfer in Closed Loop Thermosyphon - Part II: Experimental Simulation. J. of Energy in Southern Africa, vol. 18, No. 3, 2007

[3] ANDREWS. J., AKBARZADEH. A., SAUCIUC. I.: Heat Pipe Technology: Theory, Applications and Prospects. Melbourne: PERGAMON, 1996. ISBN 0080428428

[4] 3M Fluorinert ${ }^{\mathrm{TM}}$ Electronic Liquid FC-72 product information, Accessible at: http://multimedia.3m.com/mws/mediawebserver?mwsId=66666UF6EVsSyXTtnxTE5XF6EVtQEVs6EVs6EVs6E666666\&fn=prodinfo_FC72.pdf

[5] REAY, D., KEW, P.: Heat Pipes-Theory, Design and Applications. Burlington: Elsevier, 2006.ISBN-13: 978-0-7506-6754-8

[6] SAZIMA, M.: Sdileni tepla/Heat Transfer], Prague: SNTL, 1993. ISBN 80-03-00675-9. 